\title{
Cardiovascular risk factors and electrocardiographic pattern in two rural communities of Osun State in South West Nigeria
}

\author{
Patience Olayinka Akinwusi ${ }^{1}$ FWACP, Esther Olufunmilayo Asekun-Olarinmoye ${ }^{2}$ FWACP, Wasiu Olalekan Adebimpe ${ }^{2}$ FWACP, Michaeline Asuquo

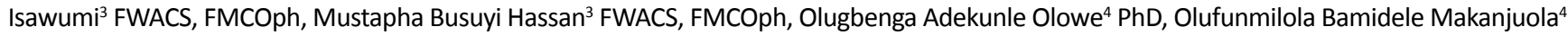 \\ FWACP, Christopher Olutayo Alebiosu ${ }^{1}$ FWACP, Taiwo Adegboyega Adewole ${ }^{5}$ FWACP, FMCP, PhD
}

\begin{abstract}
Akinwusi PO, Asekun-Olarinmoye EO, Adebimpe WO, et al. Cardiovascular risk factors and electrocardiographic pattern in two rural communities of Osun State in South West Nigeria. Curr Res Cardiol 2017;4 (2):144-150.

BACKGROUND: Urbanization and westernization now predispose rural dwellers to many of the modifiable risk factors for cardiovascular disease (CVD).

OBJECTIVES: We assessed the prevalence of CVD risk factors and electrocardiographic (ECG) pattern in 2 rural communities of Osun State, South West Nigeria.

METHODS: Descriptive cross-sectional study was carried out in March 2011 in two agrarian communities as part of the activities commemorating the World Kidney Day and World Glaucoma day. A total of 259 consenting adults (age $\geq 18$ years) participated in the study. Pre-tested, standardized, structured questionnaire was used to collect data on socio-demographic characteristics and cardiovascular risk factors. Only 64 participants had ECG done on them. Data were analyzed using the SPSS 17 software. Approval was obtained from the institution's ethical research committee.
\end{abstract}

RESULTS: Hypertension was present in $23.9 \%, 7.3 \%$ had diabetes mellitus. Left ventricular hypertrophy was present in $12.5 \%$ and $23.4 \%$ had prolonged QTc. Obesity was present in $11.5 \%$; $17.8 \%, 13.5 \%$ and $38.2 \%$ had high total cholesterol, LDL and TG levels respectively, while $49.8 \%$ had low HDL values. Multiple risk factors were present in $28.2 \%$ of the total respondents. Predictors of obesity include female gender, high total cholesterol level and low HDL levels. Predictors of hypertension include age $>45$ years, being obese, having high total cholesterol and low HDL levels.

DISCUSSION: The preponderance of multiple cardiovascular risk factors found in this study compounds the possible epidemic of CVD and its sequelae. Prolonged QTc calls for caution in administration of contraindicated drugs.

CONCLUSION: CVD risk factors are present in rural areas of Nigeria hence the need for primordial and primary prevention efforts.

Key Words: Hypertension; Diabetes mellitus; Obesity; Left ventricular hypertrophy; Multiple risk factors
The burden of cardiovascular disease (CVD) in the world is enormous and growing, and the majority of those affected are in the developing countries $(1,2)$. In 2002 , it was estimated that $29 \%$ of deaths worldwide (16.7 million deaths) were due to CVD and that $43 \%$ of global morbidity and mortality, measured in disability - adjusted life years (DALYS) was caused by CVD (3). Furthermore, $78 \%$ of global mortality and $86 \%$ of mortality and morbidity from CVD occurs in developing countries (3).

It is estimated that by $2020, \mathrm{CVD}$ will become the leading cause of the global health burden, accounting for $73 \%$ of total global mortality and $56 \%$ of total morbidity $(4,5)$. This global tide has also not spared Africa (6). In most African countries CVD is now the second most common cause of death after infectious disease, accounting for $11 \%$ of total deaths (7), and CVD is a major cause of chronic illness and disability (6). African countries therefore face a double burden of communicable diseases and CVD (6). Projections from the Global burden of Disease project suggest that from 1990 to 2020, the burden of CVD faced by African countries will double (6).

A large proportion of the victims of CVD will be middle-aged people (6). The poor will be at the receiving end as a consequence of their higher disease risk and limited access to health care (6). The financial and social costs of this CVD epidemic are likely to have a negative impact on development and the alleviation of poverty (6). Coronary Heart Disease (CHD) is gradually becoming common so also are its risk factors. A Cameroonian study showed a coronary artery disease prevalence of $1.53 \%$ with Myocardial infarction (M1) being the most frequent (43\%) (8). The cardiovascular risk factors were obesity (80\%), Hypertension (60\%), dyslipidaemia (43\%), smoking (36\%), diabetes/hyperglycaemia (26\%), and hyperuricaemia (20\%) (8).

Multiple risk factors (at least 3) were found in $67 \%$ of these patients (8).
CVD risk factors such as tobacco, refined foods and life styles are being exported to Africa through television and films by the developed countries in the name of globalization/civilization (2). Although the epidemic of CHD was heralded globally in the 1980s (9), in Africa, it is still being expected.

The major modifiable risk factors are Hypertension (BP >140/90), Diabetes Mellitus (DM), Dyslipidaemia, Tobacco use, physical inactivity, obesity, unhealthy diets (10). Other modifiable risk factors were low socioeconomic status, mental ill health, psychosocial stress, alcohol use, use of certain medications e.g. oral contraception and hormone replacement therapy, lipoprotein, left ventricular hypertrophy (LVH) (10), and use of cocaine (11). Non-modifiable risk factors are advancing age, heredity or family history, gender (male), ethnicity or race. The novel risk factors are excess homocysteine in blood, inflammation and abnormal blood coagulation (increase serum fibrinogen) (10).

In recent times kidney disease has been identified as a risk factor for CVD (12). Proteinuria and elevation of the serum creatinine even at moderate levels are risk factors for CVD (12). In patients with end stage renal disease (ESRD), the risk of CVD is $10-20$ times higher than that of the general population (13-15). Kidney disease itself is common, treatable and preventable (16).

More recently hyperuricaemia has also been incriminated in CVD predisposition (17). Oladapo et al. reported high prevalence of cardiometabolic risk factors amongst the dwellers of a rural Yoruba community in South West Nigeria (18). Similarly, in another rural community in this same tribe, hypertension, obesity, physical inactivity and low HDL-C were prevalent (19).

${ }^{1}$ Department of Medicine, College of Health Sciences, Osun State University, Osogbo, PMB 4494, Osogbo, Osun State Nigeria, ${ }^{2}$ Department of Community Medicine, College of Health Sciences, Osun State University, Osogbo, PMB 4494, Osogbo, Osun State Nigeria, ${ }^{3}$ Department of Surgery, College of Health Sciences, Osun State University, Osogbo, PMB 4494, Osogbo, Osun State Nigeria, ${ }^{4}$ Department of Medical Microbiology, College of Health Sciences, Osun State University, Osogbo, PMB 4494, Osogbo, Osun State Nigeria, ${ }^{5}$ Department of Chemical Pathology, College of Health Sciences, Osun State University, Osogbo, PMB 4494, Osogbo, Osun State Nigeria

Correspondence: Dr Patience Olayinka Akinwusi, Department of Medicine, College of Health Sciences, Osun State University, Osogbo, PMB 4494, Osogbo, Osun State, Nigeria, Telephone+2348037219451, Email pat.akinwusi@uniosun.edu.ng

Received: September 23, 2016, Accepted: July 06, 2017, Published: July 08, 2017 
Several studies have shown high prevalence of hypertension and obesity/ overweight in West Africa and also in immigrants of industralised countries from this sub-region (20).

There is therefore an urgent need to start generating data on prevalence, morbidity, mortality and risk factors of CVD in Africa. These data can then serve as template for the government to formulate concrete public health policy on CVD prevention, in order to stem the tide of this imminent CVD epidemic. We therefore embarked on this study to determine the prevalence of CVD risk factors, $\mathrm{LVH}$ inclusive (with ECG as tool) and also describe the ECG pattern in 2 rural communities of Osun State; Alajue and Ibokun, South West, Nigeria.

\section{MATERIALS AND METHODS}

\section{Study design}

This was a community-based descriptive cross-sectional study of cardiovascular risk factors carried out in these two rural communities in March 2011 during the research outreach that formed a part of the activities marking the celebration of the World Kidney Day and World Glaucoma Day.

\section{Setting}

The study areas included two rural communities in Osun State namely Alajue and Ibokun, with a total population of about five thousand people according to the 2006 Nigerian national population census. Majority of the dwellers were farmers while some were artisans and traders. There is a primary health care center in each of the communities.

\section{Participants}

The inclusion criteria were that all eligible participants be permanent residents in either community for at least 5 years, should be aged $>18$ years and were able to provide informed consent. The Nigerian demographic structure is such that only about $55 \%$ of the total population could normally be eligible (age $>18$ years) (21); then the total number of eligible population could be estimated at 2750. All consenting adults who met the inclusion criteria were screened. Due to limitation of funding in this low resource setting (research was self-funded) a subgroup of all respondents (about 25\%) was randomly selected and ECG was performed on them.

\section{Ethical approval}

Ethical approval to conduct the study was obtained from the Ethical Research Committee of Osun State University College of Health Sciences, and further permissions were given by concerned LGA authorities and community Kings. Written informed consent was obtained from each participant before commencement of the study.

\section{Data source}

This study was carried out as a part of a larger community-based screening programme to raise awareness towards kidney diseases. Two of three senatorial districts (Osun west and Osun East) were selected at random, employing simple balloting. One Local Government Area (LGA) per district and eventually one rural town (categorized as highly populated) per LGA were randomly selected also by simple balloting. These emerged as Alajue and Ibokun communities.

After paying series of advocacy visits to community gatekeepers, members of the two communities were mobilized to a town hall meeting and sensitized on the importance of screening for non-communicable diseases most especially cardiovascular diseases. At the meetings, community members eligible for the study were encouraged to come out en-masse, with the assurance that all who consented to the exercise would have it done for free.

\section{Research instruments}

An interviewer administered pre-tested questionnaire was used to collect some basic data pertaining to socio-demographic characteristics and cardiovascular risk factors among respondents. To standardize survey measurements and procedures, ten research assistants were trained with specially prepared survey manuals that conformed to recommended non-communicable disease survey protocols. Before the main study, a field test was carried out to finetune survey procedures.

\section{Operational definitions and screening procedures}

Venous blood samples for various biomarkers were collected by venepuncture after an overnight fast of $8-12 \mathrm{hr}$, stored at $12^{\circ} \mathrm{C}$ and delivered to the laboratory unit of the College of Health Sciences same day. Lipids profile and glucose levels were measured by qualified laboratory Technologists within the services of the Osun State University College of Health Sciences. Serum Creatinine was measured by enzymatic method. ECG was conducted by trained ECG Technicians and reported by two consultant cardiologists.

Hypertension- means systolic BP $\geq 140 \mathrm{mmHg}$ and/or mean diastolic BP $\geq$ $90 \mathrm{mmHg}$ or history of anti-hypertensive treatment fifteen days before the survey. Pre-hypertension is BP of $120 / 80 \mathrm{mmHg}-139 / 89 \mathrm{mmHg}$ (JNC 7) (22). Normal chemistry values used include $\mathrm{HCO}_{3}(20-30 \mathrm{mg} / \mathrm{dL}), \mathrm{Cl}-(90$ $110 \mathrm{mg} / \mathrm{dL}), \mathrm{Na}+(120-140 \mathrm{mg} / \mathrm{dL})$, Urea $(2.5-5.8 \mathrm{mmol} / \mathrm{L})$, Creatinine $(60-$ $120 \mathrm{umol} / \mathrm{l}), \mathrm{K}+(3-5 \mathrm{mmol} / \mathrm{L}), \mathrm{TG}(<1.71)$, Total Cholesterol $(<5.17), \mathrm{LDL}$ (<3.37), HDL $(>1.3)$.

\section{Measurements and calculations}

ECG Measurements: After 10 minutes rest, each subject had a resting 12 lead ECG with a long rhythm strip of lead II recorded. Three portable ECG machines (model Cardiovit AT_1ECG Machines) and a generator were utilized in the communities for the screening. A generator was needed to prevent incessant power outages from militating against the exercise. Each ECG recording was independently reported by two cardiologists. Left ventricular hypertrophy (LVH) was assessed using Araoye (23) and SokolowLyon (24) criteria independently.

Araoye criteria: $\mathrm{R}$ in lead-1 (R1) $>12 \mathrm{~mm}$, or SV2 + RV6 $\geq 35 \mathrm{~mm}$ in females ( $40 \mathrm{~mm}$ in males) with or without T-wave inversion/flattening in V5, V6.

Sokolow-Lyon criteria: SV1 + RV5 (or RV6) $\geq 35 \mathrm{~mm}$ in females (40 $\mathrm{mm}$ in males) with or without $\mathrm{T}$ wave inversion/flattening in V5, V6.

Corrected QT (QTc) was calculated for each patient using Bazett's formula (25); a normal value in females is 0.37-0.44 and in males 0.34-0.43 (26).

Body weight was measured (to the nearest $0.5 \mathrm{~kg}$ ) with the subject standing motionless on the calibrated weighing scale, with feet about $15 \mathrm{~cm}$ apart and weight equally distributed on each leg. Subjects were instructed to wear minimum outwear (as culturally appropriate) and no footwear while the weight was being measured. Height was measured (to the nearest $0.5 \mathrm{~cm}$ ) using a calibrated tape and with the subject standing in an erect position against a vertical surface, and the head positioned so that the top of the external auditory meatus was level with the inferior margin of the bony orbit.

After the subjects rested quietly for 5 minutes, blood pressure (BP) was measured in the sitting position with an appropriate-sized cuff encircling the arm. With the right arm of the subject held at the level of the heart, the maximum inflation level was determined with a mercury sphygmomanometer, using a stethoscope and a cuff of appropriate size (a cuff of larger width was used for large arms) (22).

$\mathrm{BP}$ was measured to the nearest $2 \mathrm{mmHg}$ on two occasions at an interval of one to two minutes. BP measurements were made on the right arm of each study subject. Subjects were not permitted to smoke. In cases where the two readings differed by over $10 \mathrm{mmHg}$, a third reading was obtained, and the three measurements were averaged (22). The pressures at which sound appeared and disappeared were taken as systolic blood pressure (SBP) and diastolic blood pressure (DBP) respectively. BP was classified as normal, hypertensive or isolated systolic or diastolic hypertension.

A subject was considered to have diabetes mellitus if (i) the fasting venous blood glucose $>7.0 \mathrm{mmol} / \mathrm{L}(126 \mathrm{mg} / \mathrm{dL})$, or (ii) the subject was taking a hypoglycaemic drug or insulin. Normal fasting blood glucose was taken as 3.3-5.5 mmol/L and pre-diabetes or impaired fasting glucose as 5.6-6.9 $\mathrm{mmol} / \mathrm{L}$ based on the American Diabetes Association criteria (27). Body Mass Index was calculated as weight in kilograms divided by height in meters squared. Based on their BMI, individuals were classified into four groups: thin $\left(\mathrm{BMI}<18.5 \mathrm{~kg} / \mathrm{m}^{2}\right)$, normal $\left(\mathrm{BMI}=18.5-24.9 \mathrm{~kg} / \mathrm{m}^{2}\right)$, overweight (BMI $\left.=25.0-29.9 \mathrm{~kg} / \mathrm{m}^{2}\right)$ and obese $\left(\mathrm{BMI}>30.0 \mathrm{~kg} / \mathrm{m}^{2}\right)$; all according to WHO classification.

\section{Data analysis}

The Statistical Package for Social Sciences (SPSS) software version 17 (IBM Corporation Armonk, NY, USA) was used for data entry and analysis. Validity of data was ensured by double entry and random checks for errors and outlier values. Blood chemistry variables were recorded based on normal and abnormal values for that variable. Relevant frequency distributions tables and summary indices were generated. The Chi-square test was used to demonstrate relationships between categorical variables (in only those respondents who had complete and comprehensive test results), while level of significance was set at $\mathrm{P}$-values $\leq 0.05$ and confidence interval of $95 \%$ for all inferential analysis of categorical variables. 


\section{Study limitations}

Not all the study participants completed all the necessary tests. Only 64 were able to complete all tests including ECG due to fund limitation and informed consent. Another limitation to this study was our not asking questions related to smoking of cigarette, the duration and frequency of smoking.

\section{RESULTS}

A total of 259 subjects volunteered to participate in the study. Table 1 shows the socio-demographic data of the subjects.

Mean age was $49.7(+1.6)$ years. The age range was $18-90$ years whilst mode and median were 50.0 years each respectively. Male to female ratio was 1:1.59 $(\mathrm{M}: \mathrm{F}=1: 1.59)$

Table 2 shows the risk factors for CVS disease. The total number of patients with high blood pressure (BP) $\geq 140 / 90$ was 62 (23.9\%), $48(18.5 \%)$ had ever taken anti-hypertensives on regular basis before. A total of $28(10.8 \%)$ had pre-hypertension (BP - 120/80 -139/89) and this included $15(15.0 \%)$ of males and $13(8.2 \%)$ of females. A total of 19 respondents had DM confirmed by FBS, and this included $8(3.1 \%)$ of male and $11(4.2 \%)$ of female respondents.

Thirty-seven (14.3\%) have impaired fasting glucose, out of which $16(43.2 \%)$ were males and $21(56.8 \%)$ were females. Thirty (11.5\%) were obese, 236 $(91.1 \%)$ said they were involved in daily exercises lasting at least 30 minutes, $46(17.8 \%), 35(13.5 \%)$ and $99(38.2 \%)$ had high total cholesterol, LDL and TG levels respectively, while only 129 (49.8\%) had low HDL values. Age and sex were found to be statistically significantly associated with hypertension and obesity respectively.

The mean of the total values for the various parameters were systolic BP $138.9 \pm 5.7 \mathrm{mmHg}$, diastolic BP $79.9 \mathrm{mmHg} \pm 4.9$, total cholesterol 4.3 $\mathrm{mmol} / \mathrm{L} \pm 3.0$, TG $1.6 \mathrm{mmol} / \mathrm{L} \pm 0.8, \mathrm{HDL} 1.4 \mathrm{mmol} / \mathrm{L} \pm 0.7$ and LDL $1.9 \mathrm{mmol} / \mathrm{L} \pm 1.2$, urea $4.2 \mathrm{mmol} / \mathrm{L} \pm 2.2$, creatinine $0.45 \mathrm{umol} / 1 \pm 0.035$, FBS $5.0 \mathrm{mmol} / \mathrm{L} \pm 1.6, \mathrm{~K}+3.9 \mathrm{mmol} / \mathrm{L} \pm 0.82$ waist circumference in all respondents $86.24 \mathrm{~cm} \pm 12.3$, in males $85.8 \mathrm{~cm} \pm 2.4$ and in females $86.5 \mathrm{~cm}$ $\pm 3.5 \mathrm{BMI}$ in males $23.1 \mathrm{~kg} / \mathrm{m}^{2} \pm 1.3$ and in females $23.6 \mathrm{~kg} / \mathrm{m}^{2} \pm 2.6$. The urea was elevated in $12(4.6 \%)$ and creatinine in only $1(0.4 \%)$

Table 3 shows the electrocardiography (ECG) result of the patients. The ECG pattern of majority of these rural dwellers was normal. Majorities $(82.8 \%)$ of the people had normal heart rates and were in normal sinus rhythm whilst $9.4 \%$ and $7.8 \%$ had sinus bradycardia and sinus tachycardia respectively. First degree heart block was present in 4 (6.3\%) whilst one subject $(1.6 \%)$ had second degree heart block (Type 1). The QRS frontal plane electrical axis was normal in $76.5 \%$ of the people with $10.9 \%$ having left axis deviation (LAD), another $4.7 \%$ having right axis deviation (RAD) and $7.8 \%$ having indeterminate axis.

The ST segment was normal in $95.3 \%$ of the subjects and only $4.7 \%$ had non-significant ST changes; similarly, the T wave was also normal in $85.9 \%$, inverted in $7.9 \%$ and nonspecific in $6.2 \%$. By Araoye criteria, no LVH was found. However, a total of $1(1.6 \%)$ of male and $7(11.0 \%)$ of females had

TABLE 1

Socio-demographic data of respondents $(n=259)$

\begin{tabular}{ccc}
\hline Variables $(\mathbf{n}=\mathbf{2 5 9})$ & Frequency & Percentage \\
\hline Age group & & \\
$18-29$ (or $\leq 29$ years) & 36 & 13.9 \\
$30-49$ & 75 & 29.0 \\
$50-69$ & 109 & 42.0 \\
$70-89$ & 38 & 14.6 \\
90 above & 1 & 0.4 \\
Mean age $49.7 \pm$ (1.6) years & & \\
Sex & & \\
Male & 100 & 38.6 \\
Females & 159 & 61.4 \\
& & \\
Occupation & & 42.9 \\
Trading & 111 & 32.4 \\
Farming & 84 & 6.9 \\
Artisans & 18 & 17.8 \\
Others & 46 & \\
\hline
\end{tabular}

TABLE 2

Risk factors for CVD (n=259)

$$
\text { Risk variables }
$$

Frequency Percentage

Body Mass Index category

Overweight

$$
\text { Obesity }
$$

Mean Body Mass Index was $23.4(+4.9) \mathrm{kg} / \mathrm{m}^{2}$.

Usually have daily exercises lasting at least $30 \mathrm{mins}$

Past medical history

Past history of High Blood Pressure

Family history of hypertension

Past history of Diabetes Mellitus

BP measurements $(\mathrm{mmHg})$

$\begin{array}{ccc}\text { Normal } & 197 & 76.1 \\ \text { Hypertension } & 34 & 13.1 \\ \text { Systolic hypertension } & 17 & 6.6 \\ \text { Diastolic hypertension } & 11 & 4.2 \\ \text { Hypertension - Total } & 62 & 23.9 \\ \text { Pre-hypertension } & 28 & (10.8)\end{array}$

Fasting blood sugar

Low

High (Diabetes mellitus)

Impaired fasting glucose

\section{Dyslipidaemia}

Total cholesterol

$$
\text { Normal }
$$

High

Triglyceride

$$
\begin{aligned}
& \text { Normal } \\
& \text { High }
\end{aligned}
$$

Low Density Lipoprotein

$$
\text { Normal }
$$

$$
\text { High }
$$

No class

High Density Lipoprotein

$$
\text { Normal }
$$

$$
\text { Low }
$$


LVH by Sokolow-Lyon criteria. The mean QTc was $0.42 \pm 0.04$.

Table 4 showed that a statistically significant association was found between obesity and gender of respondents, and blood pressure $(p<0.05)$ while none existed between obesity and HDL levels, total cholesterol levels and fasting blood glucose level. $(p>0.05)$. A statistically significant association was found between hypertension and age of respondents $(p<0.05)$ while none existed between hypertension and gender, HDL levels, total cholesterol levels and fasting blood glucose level. ( $p>0.05$ ). Similarly, there was no statistically significant association when those with normal and prolonged QTc were compared with either hypertension or obesity as a status $(p>0.05)$.

While age is not a predictor of obesity (OR 1.08), respondents older than 45 years of age were three $(1 / 0.34)$ times more likely to have developed hypertension compared to those respondents less than 45 years old (OR $0.34,95 \%$ CI $0.192-0.616, p-0.001)$ and this observation was found to be statistically significant.

Female respondents were 1.4 times more likely to be obese compared to male (OR 1.43, 95\% CI 0.651-3.157, p-0.188); however, gender was not found to be a predictor of hypertension (OR 0.87). Obese respondents were 1.7 $(1 / 0.60)$ times more likely to become hypertensive compared to the nonobese (OR 0.60, 95\% CI 0.284-1.291, p-0.102).

Respondents with high total cholesterol levels were 1.5 times more likely to

\section{TABLE 3}

ECG pattern of respondents $(\mathrm{N}=64)$

\begin{tabular}{|c|c|c|}
\hline Variables & $\mathrm{N}$ & $\%$ \\
\hline $\begin{array}{c}\text { Heart rate/minute } \\
<60 \\
60-100 \\
>100\end{array}$ & $\begin{array}{c}6 \\
53 \\
5\end{array}$ & $\begin{array}{c}9.4 \\
82.8 \\
7.8\end{array}$ \\
\hline $\begin{array}{c}\text { Rhythm } \\
\text { Normal Sinus } \\
\text { Sinus bradycardia } \\
\text { Sinus tachycardia }\end{array}$ & $\begin{array}{c}53 \\
6 \\
5\end{array}$ & $\begin{array}{c}82.8 \\
9.4 \\
7.8\end{array}$ \\
\hline $\begin{array}{c}\text { QRS axis } \\
\text { Normal } \\
\text { LAD } \\
\text { RAD } \\
\text { Indeterminate }\end{array}$ & $\begin{array}{c}49 \\
7 \\
3 \\
5\end{array}$ & $\begin{array}{c}76.6 \\
10.9 \\
4.7 \\
7.8\end{array}$ \\
\hline $\begin{array}{l}\text { QTC interval } \\
\text { Normal } \\
\text { Prolonged }\end{array}$ & $\begin{array}{l}49 \\
15\end{array}$ & $\begin{array}{l}76.6 \\
23.4\end{array}$ \\
\hline $\begin{array}{l}\text { ST segment } \\
\text { Normal } \\
\text { Others }\end{array}$ & $\begin{array}{c}61 \\
3\end{array}$ & $\begin{array}{c}95.3 \\
4.7\end{array}$ \\
\hline $\begin{array}{c}\text { T wave } \\
\text { Normal } \\
\text { Inverted } \\
\text { Non specific }\end{array}$ & $\begin{array}{c}55 \\
5 \\
4\end{array}$ & $\begin{array}{c}85.9 \\
7.8 \\
6.3\end{array}$ \\
\hline $\begin{array}{c}\text { Pathological q wave } \\
\text { Absent } \\
\text { Present }\end{array}$ & $\begin{array}{c}64 \\
0\end{array}$ & $\begin{array}{c}100.0 \\
0\end{array}$ \\
\hline $\begin{array}{c}\text { Conduction } \\
1^{\text {st }} \text { degree heart block } \\
2^{\text {nd }} \text { degree heart block } \\
\text { Normal }\end{array}$ & $\begin{array}{c}4 \\
1 \\
59\end{array}$ & $\begin{array}{c}6.3 \\
1.6 \\
92.2\end{array}$ \\
\hline $\begin{array}{l}\text { Sokolow-Lyon } \\
\text { Male normal } \\
\text { Male LVH } \\
\text { Female normal } \\
\text { Female LVH }\end{array}$ & $\begin{array}{c}26 \\
1 \\
30 \\
7\end{array}$ & $\begin{array}{c}40.5 \\
1.6 \\
46.9 \\
11.0\end{array}$ \\
\hline $\begin{array}{c}\text { Ectopics } \\
\text { Nil } \\
\text { Occasional VPCs }\end{array}$ & $\begin{array}{c}60 \\
4\end{array}$ & $\begin{array}{c}93.8 \\
6.3\end{array}$ \\
\hline $\begin{array}{c}\text { Araoye } \\
\text { Male normal } \\
\text { Male LVH } \\
\text { Female normal } \\
\text { Female LVH }\end{array}$ & $\begin{array}{c}27 \\
0 \\
37 \\
0\end{array}$ & $\begin{array}{c}42.1 \\
0 \\
57.9 \\
0\end{array}$ \\
\hline
\end{tabular}

TABLE 4

Associations between categorical variables and CVS risk factors on bivariate and logistic regression $(\mathrm{N}=259)$

\begin{tabular}{|c|c|c|c|c|c|c|}
\hline \multicolumn{7}{|c|}{ Bi-variate analysis $(n=259)$} \\
\hline \multirow{3}{*}{ Variables } & \multicolumn{3}{|c|}{ Obesity } & \multicolumn{3}{|c|}{ Hypertension } \\
\hline & \multicolumn{2}{|c|}{ Proportion } & \multirow{2}{*}{$\begin{array}{l}\text { Statistics } \\
\mathrm{X}^{2,} \mathrm{P} \text { value }\end{array}$} & \multicolumn{2}{|c|}{ Proportion } & \multirow{2}{*}{$\begin{array}{l}\text { Statistics } \\
\mathrm{X}^{2}, \mathrm{P} \text { value }\end{array}$} \\
\hline & Yes & No & & Yes & No & \\
\hline \multicolumn{7}{|l|}{ Age (years) } \\
\hline$<45$ & $\begin{array}{c}11 \\
(10.9)\end{array}$ & $\begin{array}{c}90 \\
(89.1)\end{array}$ & 1.896 & $\begin{array}{c}20 \\
(19.8)\end{array}$ & $\begin{array}{c}81 \\
(80.2)\end{array}$ & 1.557 \\
\hline$>45$ & $\begin{array}{c}16 \\
(10.1)\end{array}$ & $\begin{array}{c}142 \\
(89.9)\end{array}$ & 0.059 & $\begin{array}{c}66 \\
(41.8)\end{array}$ & $\begin{array}{c}92 \\
(58.2)\end{array}$ & 0.001 \\
\hline \multicolumn{7}{|l|}{ Gender } \\
\hline Male & $\begin{array}{c}13 \\
(13.0)\end{array}$ & $\begin{array}{c}87 \\
(87.0)\end{array}$ & 2.105 & $\begin{array}{c}31 \\
(31.0)\end{array}$ & $\begin{array}{c}69 \\
(69.0)\end{array}$ & 0.244 \\
\hline Female & $\begin{array}{c}15 \\
(9.4)\end{array}$ & $\begin{array}{c}144 \\
(90.6)\end{array}$ & 0.05 & $\begin{array}{c}54 \\
(34.0)\end{array}$ & $\begin{array}{l}105 \\
(66.0)\end{array}$ & 0.621 \\
\hline $\begin{array}{l}\text { Blood pressure } \\
\text { level }\end{array}$ & & & & - & - & - \\
\hline Normal & $\begin{array}{c}25 \\
(12.7)\end{array}$ & $\begin{array}{c}172 \\
(87.3)\end{array}$ & 4.543 & & & \\
\hline High & $\begin{array}{c}12 \\
(19.4)\end{array}$ & $\begin{array}{c}50 \\
(80.6)\end{array}$ & 0.05 & & & \\
\hline \multicolumn{7}{|l|}{$\mathrm{HDL}$} \\
\hline Normal & $\begin{array}{c}20 \\
(15.3)\end{array}$ & $\begin{array}{c}110 \\
(84.7)\end{array}$ & 2.058 & $\begin{array}{c}49 \\
(37.7)\end{array}$ & $\begin{array}{c}81 \\
(62.3)\end{array}$ & 2.17 \\
\hline Low & $\begin{array}{c}14 \\
(10.8)\end{array}$ & $\begin{array}{c}115 \\
(89.2)\end{array}$ & 0.842 & $\begin{array}{c}40 \\
(31.0)\end{array}$ & $\begin{array}{c}89 \\
(69.0)\end{array}$ & 0.338 \\
\hline \multicolumn{7}{|l|}{$\begin{array}{c}\text { Total cholesterol } \\
\text { level }\end{array}$} \\
\hline Normal & $\begin{array}{c}23 \\
(10.6)\end{array}$ & $\begin{array}{c}194 \\
(89.4)\end{array}$ & 2.403 & $\begin{array}{c}73 \\
(34.3)\end{array}$ & $\begin{array}{c}140 \\
(65.7)\end{array}$ & 0.51 \\
\hline High & $3(7.1)$ & $\begin{array}{c}39 \\
(92.9)\end{array}$ & 0.326 & $\begin{array}{c}12 \\
(26.1)\end{array}$ & $\begin{array}{c}34 \\
(73.9)\end{array}$ & 0.522 \\
\hline \multicolumn{7}{|l|}{ Glucose level } \\
\hline Normal & $\begin{array}{c}27 \\
(11.3)\end{array}$ & $\begin{array}{c}213 \\
(88.7)\end{array}$ & 0.354 & $\begin{array}{c}79 \\
(32.9)\end{array}$ & $\begin{array}{c}161 \\
(67.1)\end{array}$ & 0.014 \\
\hline High & $\begin{array}{c}3 \\
(15.8)\end{array}$ & $\begin{array}{c}16 \\
(84.2)\end{array}$ & 0.552 & $6(31.6)$ & $\begin{array}{c}13 \\
(68.4)\end{array}$ & 0.905 \\
\hline \multicolumn{7}{|l|}{$\begin{array}{l}\text { QTc interval } \\
(\mathrm{N}=64)\end{array}$} \\
\hline Normal & $7(14.3)$ & $\begin{array}{c}42 \\
(85.7)\end{array}$ & 1.505 & $9(18.4)$ & $\begin{array}{c}40 \\
(91.6)\end{array}$ & 0.013 \\
\hline Prolonged & $\begin{array}{c}3 \\
(20.0)\end{array}$ & $\begin{array}{c}12 \\
(80.0)\end{array}$ & 0.681 & $\begin{array}{c}3 \\
(20.0)\end{array}$ & $\begin{array}{c}12 \\
(80.0)\end{array}$ & 0.908 \\
\hline \multicolumn{7}{|c|}{ Binary logistic regression } \\
\hline \multirow{2}{*}{ Variable } & \multicolumn{3}{|c|}{ Obesity } & \multicolumn{3}{|c|}{ Hypertension } \\
\hline & OR & $95 \% \mathrm{CI}$ & P value & OR & $95 \% \mathrm{CI}$ & P value \\
\hline \multirow[t]{2}{*}{$\begin{array}{c}\text { Age (reference } \\
\text { category }=>45 \\
\text { years) }\end{array}$} & 1.08 & 0.481 & 0.419 & 0.34 & 0.192 & 0.001 \\
\hline & & 2.442 & & & 0.616 & \\
\hline \multirow[t]{2}{*}{$\begin{array}{c}\text { Gender } \\
\text { (reference } \\
\text { category=male) }\end{array}$} & 1.43 & 0.651 & 0.188 & 0.87 & 0.511 & 0.313 \\
\hline & & 3.157 & & & 1.493 & \\
\hline $\begin{array}{c}\text { Obesity ( } \\
\text { reference } \\
\text { category=obese) }\end{array}$ & - & - & - & 0.6 & $\begin{array}{l}0.284 \\
1.291\end{array}$ & 0.102 \\
\hline $\begin{array}{l}\text { Total cholesterol } \\
\text { level ref. } \\
\text { category==low) }\end{array}$ & 1.54 & 0.441 & 0.264 & 1.47 & 0.721 & 0.144 \\
\hline
\end{tabular}


5.386

3.024

\section{HDL level}

reference

1.34

0.804 category==high)
0.718

3.103
2.252

\section{Percentage among those with multiple risks $(n=73)$}

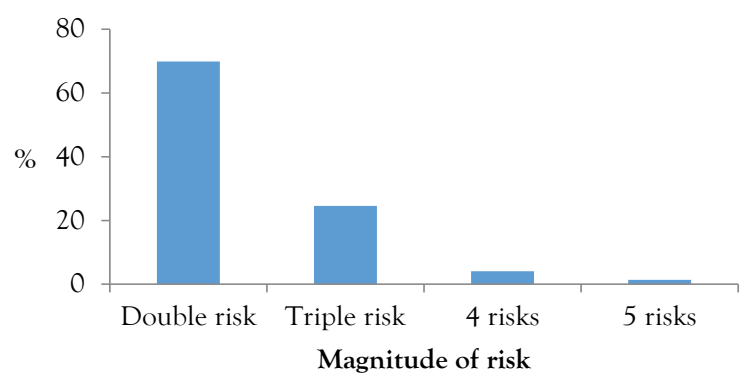

Figure 1) Risk factors considered included hypertension, diabetes, high total cholesterol, Obesity, high LDL, low HDL and LVH

be obese compared to those with normal or low total cholesterol level (OR 1.54, 95\% CI 0.441-5.386, p-0.264). Likewise, respondents with high total cholesterol levels were also 1.5 times more likely to be hypertensive compared to those with normal or low total cholesterol level (OR 1.47, 95\% CI 0.7213.024, p-0.144).

Respondents with a low HDL level were 5 times more likely to be obese compared to those with high HDL (OR 1.49, 95\%CI 0.718-3.103, p-0.144). Likewise, respondents with low HDL levels were 1.3 times more likely to be hypertensive compared to those with normal HDL levels (OR 1.34, 95\% CI, 0.804-2.252, $\mathrm{p}-0.130$ ), though these observations were not statistically significant

Figure 1 shows the pattern of multiple risk factors among the respondents. A total of 73 respondents (28.2\%) had multiple risk factors; 51 (69.9\%) had double while $18(24.7 \%)$ had triple risk factors. Others with greater than triple risk factors are as shown in Figure 1.

\section{DISCUSSION}

The prevalence of hypertension and other CVS risk factors in Nigeria is on the upward trend portending increase in morbidity and mortality attributable to CVD. This current study supports this dangerous trend as reported in some other rural communities across the nation. $(18,19,28)$. This study showed a systemic hypertension prevalence rate of $23.9 \%$ in the two rural communities studied. The total prevalence of hypertension in this study included the patients with known hypertension as they still had their $\mathrm{BP}$ elevated showing poor BP control either due to inadequate dosing or poor drug compliance. This shows an increase when compared with an earlier community study in another rural area amongst the same Yoruba tribe of South West Nigeria where a prevalence of $20.8 \%$ was reported (18). Other studies in Nigeria reported the rural prevalence of hypertension in both sexes to be between 13.5 and $46.4 \%$ (29).

An isolated study however showed a $66.4 \%$ prevalence of hypertension in a rural Yoruba community (19). This higher prevalence was because majority $(56.7 \%)$ of the participants were older, aged between $60-79$ years; mean age of $66.77 \pm 12.06$ years, age range $40-88$ years whilst the subjects in this current study have an age range of $18-90$ years and a mean age of $49 \pm 1.6$. The prevalence of hypertension increases with age $(29,30)$. The association between hypertension and age $>45$ years was statistically significant (OR 0.34 , $95 \%$ CI $0.192-0.616, p=0.001$ ). This is supported by all other previous studies that showed a good correlation between age and hypertension in which BP increased steadily with age $(29,30)$. Other predictors of hypertension in this study included high total cholesterol and low HDL levels as shown in Table 4. Respondents with high total cholesterol levels were 1.5 times more likely to be hypertensive compared to those with normal or low total cholesterol level (OR 1.47, 95\% CI 0.721-3.024, p-0.144). Likewise, respondents with low HDL levels were 1.3 times more likely to be hypertensive compared to those with normal HDL levels (OR 1.34, 95\% CI, 0.804-2.252, p-0.130), though these observations were not statistically significant.

The level or awareness of hypertension was high as 48 (77.4\%) of the 62 affected subjects admitted to having taken regular anti-hypertensives before. This contrasts with previous studies in Nigeria that showed low levels of awareness which ranged from $3.5 \%$ to $30 \%$ (29).

This may be due to regular interaction of health workers, students and researchers with these two communities. The mean age of these rural dwellers was $49.7 \pm 1.6$ years. This is also very close to the mean age of $42.1 \pm$ 21.6 years of the subjects in one of the earlier Nigerian studies (18).

Obesity was also found to be statistically significantly associated with hypertension in this study $(\mathrm{p}=0.050)$; this is supported by other studies $(30,31)$. Obese respondents were $1.7(1 / 0.60)$ times more likely to become hypertensive compared to the non-obese (OR 0.60, 95\% CI 0.284-1.291, $\mathrm{p}-0.102)$. Obesity was found in $11.5 \%$ of the subjects while overweight was present in $19.6 \%$ of them. This is similar to $11.12 \%$ obesity obtained in a study conducted in the South East of Nigeria using selected urban and rural Igbo communities (32) but much higher than the 3.9\% obtained for general obesity in another study (18). Our finding on the prevalence of obesity also falls within the range of the prevalence of obesity in Nigeria as reported in a systematic review of literature by Chukwonye et al. (33).

Obesity was significantly associated with the female sex $(p=0.050)$. Female respondents were 1.4 times more likely to be obese compared with males (OR 1.43, 95\% CI 0.61-3.157, p - 0.188). Although more females (2.4\%) were obese in the earlier study as against $1.5 \%$ of the males, there was however no association calculated with which to compare our study (18). A study done in Latin America and the Caribbean lends credence to this with the females having higher prevalence of obesity than the males (34). This study also showed that high total cholesterol level and low HDL were predictors of obesity (Table 4). A chinese study supports that low HDL was associated with obesity and overweight (BMI) and the association was stronger with central obesity using waist circumference $(\mathrm{p}<0.001)(35)$. Respondents with high total cholesterol levels were 1.5 times more likely to be obese compared to those with normal or low total cholesterol level (OR 1.54, 95\% CI 0.441 5.386, p-0.264). Similarly, respondents with a low HDL level were 5 times more likely to be obese compared to those with high HDL (OR 1.49, 95\%CI $0.718-3.103, \mathrm{p}-0.144)$. A 26 year follow up of participants in the Framingham Heart Study found obesity to be an independent risk factor for cardiovascular diseases in both sexes (36). This was similarly observed amongst Finnish men and women after adjusting for confounding factors (37). About onetenth of our respondents had pre-hypertension; this is much lower than the prevalence of $31.0 \%$ reported in the study in American adults (38).

This is expected as westernization of diet and lifestyle is at its peak in America. A meta-analysis from 18 prospective cohort studies showed elevated CVD risk in patients with pre-hypertension, after adjusting for multiple cardiovascular risk factors (39). Diabetes mellitus was detected in 19 (7.3\%) of the subjects, lower prevalence was reported in rural areas in the South West and South East of Nigeria (2.5\%, 4.8\%, and 3.6\% respectively) $(18,19,29)$. Impaired fasting glucose was also present in $14.8 \%$ of the people. These people with impaired glucose are likely to progress to full blown diabetes mellitus if lifestyle changes are not adopted. Hypercholesterolemia was found in $46(17.8 \%)$ of the patients; 99 (38.2\%) had hypertriglyceridemia and 35 $(13.5 \%)$ had high LDL. This contrasts with lower figures of $2.5 \%, 1.9 \%$ and $0.9 \%$ reported for hypercholesterolemia, hypertriglyceridemia and high LDL respectively in an earlier study (18). This may suggest that the newly studied rural communities have adopted more westernized lifestyle. In this study also, $49.8 \%$ had low HDL as against $43.1 \%$ and $30.0 \%$ with low HDL in other studies in the same tribe $(18,19)$. The serum creatinine and urea were elevated in $1(0.3 \%)$ and $12(4.6 \%)$ respectively. Elevated serum urea without concomitant increase in serum creatinine is most likely due to dehydration, more so that the study was carried out during the hot season of the year Only $0.3 \%$ was deemed to have had renal impairment which itself is a risk factor for cardiovascular disease (12).

Physical activity lasting at least 30 minutes a day was very common in the respondents with $236(91.1 \%)$ of them belonging into this group. This is similar to the earlier study in which $96.8 \%$ of the rural participants were also physically active (18). This is not unexpected as there are no commercial vehicles for intra village transportation, also the road in Alajue was not motorable as at the time of data collection so people had to trek or ride bicycles to their farms and for moving around. This was advantageous to the villagers as regular physical activity and a normal weight can reduce the risk of cardiovascular disease (37). Another study however showed a lower proportion, $70.2 \%$ of the rural community was physically active; the plausible explanation here was the subjects were much older (19).

The ECG pattern of majority of these rural dwellers were normal as shown 
in Table 3, this was expected as they were apparently normal healthy subjects within the community. Majorities $(82.8 \%)$ of the people had normal heart rates and were in normal sinus rhythm whilst $9.4 \%$ and $7.8 \%$ had sinus bradycardia and sinus tachycardia respectively. Sinus bradycardia occurs in people accustomed to exercise such as trained athletes (40), we opine that those with sinus bradycardia might be doing more trekking and farming activities than others. Sinus tachycardia could also have occurred in some subject's due to fear since they had never had ECG run on them before.

First degree heart block was present in 4 (6.3\%) whilst one subject (1.6\%) had second degree heart block (Type 1). Morbitz type 1 heart block originally considered to be benign has now been found not to be benign in those aged $\geq 45$ years (41). The QRS frontal plane electrical axis was normal in $76.5 \%$ of the people with $10.9 \%$ having left axis deviation (LAD), another $4.7 \%$ having right axis deviation (RAD) and $7.8 \%$ having indeterminate axis. Although majority of the subjects had their QRS frontal plane electrical axis within the normal range but their percentage $(76.5 \%)$ was lower than the $97.0 \%$ reported in normal healthy adult Nigerians by Araoye (42); conversely the proportion of those with LAD (10.9\%) and RAD (4.7\%) were higher in this study than the $2.9 \%$ and $0.1 \%$ obtained respectively in the earlier study (42). The LAD is likely to be because $57.0 \%$ of this study subjects were in the age group $\geq 50$ years as shown in Table 1 . There is a normal leftward shift of the QRS axis with age, RAD could also be a variant of normal (43). The indeterminate axis seen in $7.8 \%$ of the subjects however calls for more investigations of those affected as this is rare in normal subjects and when present it indicates serious cardiac condition (43). There were no atrial premature complexes but occasional ventricular premature complexes (VPCs) occurred in $4(6.3 \%)$ of the subjects. Occasional VPCs can be found in normal subjects but as long as they are not frequent or lethal. This has been reported in $1-4 \%$ of the normal population on regular 12 lead resting ECG (44), and in $40-75 \%$ of subjects on $24-48$ hours holter monitoring (45).

There was no ECG evidence of ischaemic heart disease in any of the subjects as majority (95.3\%) of them had normal ST segment, only $4.7 \%$ had nonsignificant ST changes; similarly, the $\mathrm{T}$ wave was also normal in $85.9 \%$, inverted in $7.9 \%$, nonspecific in $6.2 \%$ and there were no pathological q waves. Although ischaemic heart disease was not found in these two communities but there is already a constellation of risk factors within these rural communities buttressing an earlier study that the rural communities are also not left out of the epidemiologic transition from communicable diseases to non-communicable diseases (NCDs) (18). Also, it had been shown in our earlier study that the NCDs are now emerging as the most common cause of hospital admission in Nigeria (46). Furthermore, hypertension and its related complications have been shown to be the commonest cause of sudden death in Nigeria (47)

QTc interval was prolonged in $23.4 \%$, this is rather high and caution must be exercised in administering drugs that are known to prolong QTc interval especially antibiotics such as the macrolides (Erythromycin>Clarith romycin>Azithromycin), trimetoprim-sulfamethoxazole, pentamidine, azoles and the fluoroquinolones (sparfloxacin, ciprofloxacin) to them in these two communities so as to avoid lethal arrhythmias, torsades des pointes and sudden death (48). Also, the $23.4 \%$ may not be representative of the community because only $25 \%$ of those screened had ECG done and this is a limitation of the study. It is also pertinent to note that none of the patients who had ECG was on any illicit drug such as methadone, halofantrine or any other drugs that could prolong the QTc.

This study appears to be the first in Nigeria that will do a community survey incorporating ECG.

This is because of logistic problems associated with this, some of these we were able to surmount by carrying portable ECG machines and a generator for the supply of electricity into these two communities. The seemingly apparently normal rural dwellers were found to have the above stated ECG abnormalities. It is also the first time LVH will also be assessed alongside with some other risk factors. LVH on its own predisposes an individual to sudden death irrespective of its cause on account of the lethal arrhythmias it induces hence aggressive management of those with it is the ultimate goal (49-51).

The preponderance of multiple risk factors as seen in this study further compounds the possible epidemic of CVD and its sequelae. Multiple risk factors were present in 73 respondents (28.2\%) and 51 (69.9\%) had double while $18(24.7 \%)$ had triple risk factors (Figure 1$)$. This is higher than what was reported in an earlier study amongst a rural Yoruba community in South West Nigeria in which multiple cardiometabolic risk factors were reported in $2.1 \%$ of men and $2.7 \%$ of women (18). It is also noteworthy that a minor percentage had four or five risk factors as shown in Figure 1. This may be an indication of continuing urbanization and westernization of our rural communities. A study in Abuja among the aboriginal inhabitants of Abuja comparing the prevalence of cardiovascular risk factors among the urban population with that of the rural population corroborates this; despite the same ancestry of these two communities, urbanization increased the prevalence of most of the traditional CVS risk factors (52).

This study also showed that $23.4 \%$ of respondents that had ECG done on them had prolonged QTc in both communities. This is a significant finding, because prolonged QTc calls for caution in the administration of contraindicated drugs. Therefore, this work has the potential of furthering our understanding and makes primary prevention efforts in rural areas of Nigeria more feasible.

All the subjects identified to be having these risk factors were counseled and sent to our cardiology clinic at the Ladoke Akintola University Teaching Hospital for more thorough investigations and appropriate treatment; after which they were sent back to the primary health centre or comprehensive health centre to continue their treatment and follow up. A few of the patients however opted for continuation of their treatment in the teaching hospital and are still being followed up.

\section{CONCLUSION}

It is important to conclude that obesity/overweight, physical inactivity, existence of hypertension, pre-hypertension, diabetes, impaired fasting glucose, and dyslipidemia are all modifiable risk factors that could be tackled to prevent emergence of cardiovascular diseases in epidemic proportions. Concerted effort must be made by all stakeholders in the health sector to increase awareness and knowledge among the rural communities where there is usually limited access to electronic and print media as a means of health education. Thus, stakeholders should devise acceptable methods of reaching these remote areas with appropriate messages that would address modifiable risk factors for non-communicable diseases as well as strengthen the health systems to take care of non-modifiable and other risk factors and determinants thereby preventing a future epidemic of CVD.

\section{ACKNOWLEDGEMENT}

We appreciate the cooperation given to us by the community kings, elders as well as all the participants in the two communities of Alajue and Ibokun. We are also grateful to the Medical Laboratory Technologists of the College of Health-Sciences, Osun State University Osogbo and those of Ladoke Akintola University of Technology Teaching Hospital, Osogbo for the active role they played during the period of data collection

\section{FUNDING SOURCE}

The authors funded the research.

\section{DISCLOSURES}

We declare there are no competing interests.

\section{REFERENCES}

1. Beaglehole R, Yach D. Globalisation and the prevention and control of non-communicable disease. The neglected chronic diseases of adults. Lancet 2003;362:903-08.

2. Mbewu AD. Can developing country systems cope with the epidemics of cardiovascular disease? Paper presented at the Heart. Health Conference, New Delhi, India 1998

3. WHO (World Health Organization). The World Health Report of 2002. Reducing risks, promoting healthy life. Geneva. WHO.

4. Murray CJ, Lopez A. The global burden of disease. Washington, DC: World Bank 1996.

5. Reddy KS, Yusuf S. Emerging epidemic of cardiovascular disease in developing countries. Circulation 1998;97:596-01.

6. Mbewu A, Mbanya J. Disease and mortality in sub-Saharan Africa. 2nd Edition. The World Bank. 2006.

7. WHO (World Health Organisation). The World Health Report of 1999 Making a difference. Geneva: WHO.

8. Mbanya JC, Minkoulou E, Salah J, et al. The prevalence of Hypertension in Rural and urban Cameroun. Int J Epidem 1998;27:181-85. 
9. Ogunnowo PO, Odesanmi WO, Andy JJ. Coronary Artery Pathology of III consecutive Nigerians. Trans Roy Soc Trop Med Hyg 1986;80:923-26.

10. Black HR. Cardiovascular risk factors chapter 3.

11. Schwartz BG, Rezkalla S, Kloner RA. Contemporary reviews in cardiovascular medicine. Circulation. 2010;122:2558-69.

12. Mann JF, Gerstein HC, Pogue J, et al. Renal insufficiency as a predictor of cardiovascular outcomes and the impact of ramipril. The HOPE randomized trial. Ann Intern Med 2001;134:629-36.

13. Foley RN, Parfrey PS, Sarnak MJ. Clinical epidemiology of cardiovascular disease in chronic renal disease. Am J kidney Dis 1998;32:S112-19.

14. Baigent C, Burbury K, Wheeler D. Premature Cardiovascular disease in chronic renal failure. Lancet 2000;356:147-52

15. Parfrey PS, Foley RN. The clinical epidemiology of cardiac disease in chronic renal failure. J Am Soc Nephrol 1999;10:606-15.

16. Levey AS, Andreoli SP, Dubose T, et al. Chronic kidney disease. Common, harmful and treatable. World Kidney Day 2007. J Am Soc Nephrol 2007;2:40105.

17. Feig DI, Kang D, Johnson RJ. Uric acid and cardiovascular risk. N Engl J Med 2008;359:1811-21.

18. Oladapo OO, Salako L, Sodiq O, et al. A prevalence of cardiometabolic risk factors among a rural Yoruba South-Western Nigerian population: A population-based survey. Cardiovasc J Afr 2010;21:26-1.

19. Ogunmola OJ, Adeleke O, Olaifa AO, et al. Prevalence of cardiovascular risk factors among adults without obvious cardiovascular disease in a rural community in Ekiti State, Southwest Nigeria. BMC Cardiovascular Disorders 2013,13:89.

20. Yvonne C, Laura JS, Cheryl R. Hypertension and overweight/obesity in Ghanaians and Nigerians living in West Africa and industrialized countries: A systematic review. Dennison-Himmelfarba, and Charles Agyemangb (eds) Journal of Hypertension 2014;32.

21. National Population Commission (NPC) 2006. Nigeria demographic and health survey. Calverton Maryland. NPC and ORC Macro, 45-47.

22. Chobanian AV, Bakris GL, Black HR, et al. National High Blood Pressure Education Program Coordinating Committee: Seventh report of the joint national committee on prevention, detection, evaluation, and treatment of high blood pressure. Hypertension2003;42:1206-52.

23. Araoye MA. Left ventricular hypertrophy by electrocardiography: A code system applicable to Negroes. Nig Postgrad Med J 1996;3:92-7.

24. Sokolow M, Lyon TP. The ventricular complex in left ventricular hypertrophy as observed by unipolar precordial and limb leads. Am Heart J 1949;37:16186.

25. Bazett HC. Analysis of the time relations of electrocardiograms. Heart $1918 ; 7: 353-70$

26. Araoye MA. Basic electrocardiography. (1st edn). Ilorin: Natadex, 2004:8.

27. American Diabetes Association. Diagnosis and classification of diabetes mellitus. Diabetes Care. 2010;33:S62-9.

28. Okpechi IG, Chukwuonye II, Tiffin N, et al. Blood pressure gradients and cardiovascular risk factors in urban and rural populations in Abia State, South Eastern Nigeria using the WHO stepwise approach. PLoS ONE 2013;8:e73403.

29. Ogah OS, Okpechi I, Chukwuonye II, et al. Blood pressure, prevalence of hypertension and hypertension related complications in Nigerian Africans: A review. World J Cardiol 2012;4:327-40.

30. Amira CO, Sokunbi DOB, Sokunbi A. The prevalence of obesity and its relationship with hypertension in an urban community: Data from World Kidney Day Screening Programme. Int J Med Biomed Res 2012;1:104-10.

31. Meshram II, Arlappa N, Balkrishna N, et al. Prevalence of hypertension, its correlates and awareness among adult tribal population of Kerala State, India. J Postgrad Med 2012;58:255-61.

32. Chukwuonye IJ, Chuku A, Onyeonoro UU, et al. Prevalence of abdominal obesity in Abia State, Nigeria: results of a population-based house-to-house survey Diabetes, Metabolic Syndrome and Obesity: Targets and Therapy 2013;6:285-91.

33. Chukwuonye II, Chuku A, John C, et al. Prevalence of overweight and obesity in adult Nigerians - A systematic review. Diabetes Metab Syndr Obes. 2013;6:43-47.

34. Miranda JJ, Herrera VM, Chirinos JA, et al. Major cardiovascular risk factors in Latin America: A comparison with the United States. The Latin American Consortium of Studies in Obesity (LASO). PloS One 2013;8:e54056.

35. Ge P, Dong C, Ren X, et al. The high prevalence of low HDL-cholesterol levels and dyslipidemia in rural populations in Northwestern China. PLoS ONE 2015; 10:e144104.

36. Hubert HB, Feinleib MP, McNamara PM, et al. Obesity as an independent risk factor for cardiovascular disease: A-26-year follow up of participants in the Framingham Heart Study. Circulation 1983;67:968-77.

37. Hu G, Tuomilehto J, Silventoinen K, et al. Joint effects of physical activity, body mass index, waist circumference and waist to hip ratio with the risk of cardiovascular disease among middle-aged Finnish men and women. Eur Heart J 2004;25:2212-19.

38. Wang Y, Wang QJ. The prevalence of pre-hypertension and hypertension among US adults according to the New National Committee guidelines: New challenges of the Old problem. Arch Intern Med 2004;164:2126-34.

39. Huang Y, Wang S, Cai X, et al. Pre-hypertension and incidence of cardiovascular disease: A meta-analysis. BMC Medicine 2013;11:177.

40. Corrado D, Pelliccia A, Heldbuchel $\mathrm{H}$, et al. Recommendations for interpretation of 12 lead electrocardiogram in the athlete. Eur Heart J 2010;31:243-59.

41. Shaw DB, Gowers Ji, Kekwick CA, et al. Is Morbitz type 1 atrioventricular block benign in adults? Heart 2004;90:169-74.

42. Araoye MA. Electrical axis of the heart in healthy adult Nigerians. Afr J Med Med Sci 1984;13:737-49.

43. Araoye MA. Basic electrocardiography. (2nd edn). Ibadan. Spectrum Books. $2012 ; 25$

44. Kennedy HL, Whitlock JA, Sprague MK, et al. Long-term follow-up of asymptomatic healthy subjects with frequent and complex ventricular ectopy. N Engl J Med 1985;312:193-97.

45. Ng GA. Treating patients with ventricular ectopic beats. Heart 2006;92:1707-12.

46. Okunola OO, Akintunde AA, Akinwusi PO. Some emerging issues in medical admission pattern in the tropics. Niger J Clin Pract 2012;15:51-4.

47. Akinwusi PO, Komolafe $\mathrm{AO}$, Olayemi $\mathrm{AO}$, et al. Pattern of sudden death in Ladoke Akintola University of Technology Teaching Hospital, Osogbo, South West Nigeria. Vascular Health and Risk Management 2013;9:333-39.

48. Rubinstein E, Camm J. Cardiotoxicity of fluoroquinolones. J Antimicrobial Chemother 2002;49:593-96.

49. Siegel D, Cheitlin MD, Black DM, et al. Risk of ventricular arrhythmias in hypertensive men with left ventricular hypertrophy. Am J Cardiol 1990;65:742-47.

50. Novo S, Barbagallo M, Abrignani MG, et al. Increased prevalence of cardiac arrhythmias and transient episodes of myocardial ischemia in hypertensives with left ventricular hypertrophy but without clinical history of coronary heart disease. Am J Hypertens 1997;10:843-51.

51. Spacek R, Gregor P. Ventricular arrhythmia of myocardial hypertrophy of various origins. Can J Cardiol 1997;13:455-58.

52. Adediran OS, Adebayo PB, Akintunde AA. Anthropometric differences among natives of Abuja living in urban and rural communities: correlation with other cardiovascular risk factors. BMC Research Notes 2013;6:123. 